\title{
HEART DISEASE IN CHILDREN ATTENDING SCHOOL.
}

BY

\author{
DUNSTAN BREWER, L.R.C.P., M.R.C.S., D.P.H.,
} Medical Officer of Health and School Medical Officer, of the Borough of Swindon.

One of the many problems which confronted the first school medical inspectors was that of children apparently healthy, leading normal lives, in whom murmurs and other abnormalities of the heart were revealed on medical inspection. It was known that cardiac murmurs do not necessarily indicate organic damage, but it was believed that they were departure from health of some sort, to be reckoned as defects. But of what kind and with what result we did not know. Since school medicine offered the most favourable means of watching the cardiac states of children who were not invalids, many inspectors tried by continuous and recorded observations to decide what cardiac murmurs in children really indicated and what happened to them. For this purpose the author kept a register of all cases of cardiac abnormalities discovered by inspection and endeavoured, by subsequent investigation and following up, to learn something of the nature, cause and history of these departures from the usual.

This register remained unused for many years. When the formidable question of juvenile rheumatism became dominant, the method of approaching it was found to be obscured by lack of statistical evidence even of the roughest kind on the extent and nature of the problem : and as the result of a discussion with Dr. Carey Coombs of Bristol, who was inaugurating a scheme for the control and mitigation of child rheumatism in the West of England, the existence of this register was recalled. On cursory examination it promised to throw some light upon several matters which were still uncertain.

As the register had been compiled without any preconceived idea of what use, if any, might be made of it, it was thought that it might supply a rough ides of the extent of rheumatic heart disease in children, up and about, and give some indication of the scope and nature of their needs.

The district covered was the Western part of the colliery district of Yorkshire, roughly a hundred square miles, with Wakefield as the centre. The years of observation were 1909 to 1913 . In those days, rheumatic fever was not uncommon in children, and chlorosis was met with not infrequently in girls of 11-13 years.

The number of children inspected was 22,276 , between the ages of three and fourteen. All these children were on the school register, but not all of them were actually attending school, some being brought forward especially for inspection. Chronic invalids who had never attended school, and some few who were too ill to move, are therefore missing from the register. The numbers of children of ages $4,5,7,9,10,12$ were approximately equal and their roll is nearly complete, but of the ages $3,6,8,11,14$, the numbers are not complete.

Of these 22,276 children, 952 showed some abnormality of the heart, a proportion of 4.25 per cent.

These cases are analysed in Table 1. 
TABLE 1.

Analysis of 952 Children Showing Cardiac Abnormalitims.

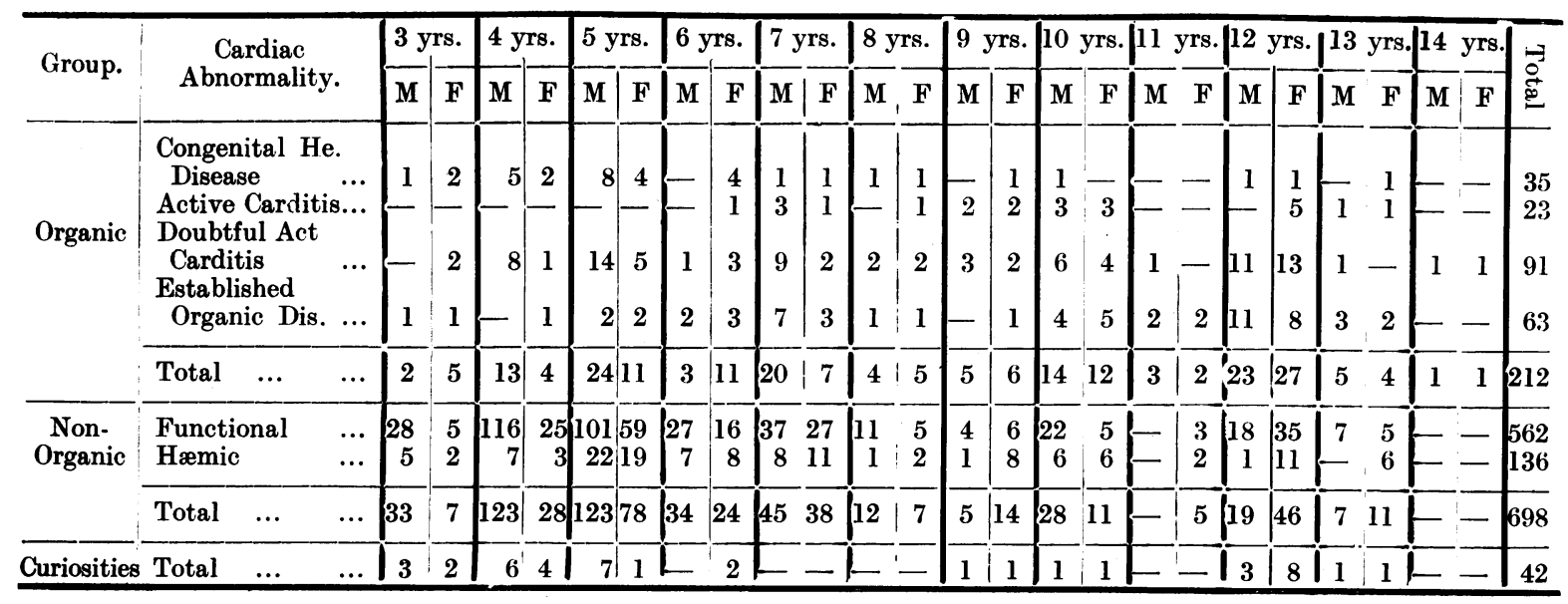

Congenital Heart Disease.

\section{Organic Group.}

35 cases of congenital heart disease were met with. In most cases the diagnosis of congenital heart disease is scarcely likely to be erroneous.* That the proportion of children with congenital heart disease should steadily diminish is, of course, to be expected, as the condition docs not arise afresh and there is considerable elimination by death. To determine the precise nature of congenital disease is always difficult, and frequently impossible, but for practical purposes these congenital heart lesions are divided into two classes; those causing severe interference with the circulation and a life of chronic invalidity followed by early death, and those which apparently interfere little, or not at all, with a life of activity.

In the original count, 23 cases were registered as unquestionably congenital disease of the heart ; of these, 16 were severe, of which two died, and seven were trivial.

Of 12 doubtful cases, two can be struck out as being temporary murmurs of no consequence ; two were undoubtedly severe congenital disease ; two were undoubted congenital disease not severe ; one was severe disease, doubtfully congenital ; and five mild disease, doubtfully congenital.

\section{Acquired Organic Heart Disease.}

86 cases were diagnosed as organic heart disease upon first inspection These cases fall naturally into two divisions - established heart disease and active carditis. Of the 86 cases, 63 were cases of established heart disease, all either valvular or partly valvular. Of these, 35 had a known history of acute rheumatism or chorea, one of nephritis and two of scarlet fever. Not all of these chronic heart cases could be considered as cripples. Three of the children

*Though it is not unlikely that some of the cases in other categories may be congenital
disease. 
died under observation; 15 of them were more or less chronic invalids, or became so at puberty ; 45 entered puberty apparently equal in their general health and activity to normal children and, while under observation, had no recurrence of rheumatism or interference with compensation. From the point of view of preventive medicine, these established heart cases are of little interest compared with the next group, the cases of active carditis.

Only 23 cases were definitely diagnosed as active carditis on first inspection, but to these must be added an equally important group of children first registered as doubtfully organic.

Of the cases registered as definite acute carditis, 13 were suffering from active chorea and 10 from other forms of rheumatism. One died; 13 developed into permanent heart disease ; five cleared up ; and four were either lost sight of, or not followed sufficiently long.

There were 91 doubtful cases. Of these, three were post-diphtheritic hearts. The others were all probably cases of acute carditis. Of these, eight were known to date from rheumatic fever, seven from scarlet fever, six from chorea and seven from acute nephritis. The origin of the remainder is obscure. Of these 91 cases, 53 were left with permanent organic heart disease, 22 remained doubtful at the end of the observation and 16 recovered.

Since active carditis in children is one of the most important of the problems of health, it will be as well to go into the subject somewhat fully in the light of the evidence which was gathered. For this purpose it will be as well to lump together the cases which were diagnosed definitely at once and those in which a judgment was either suspended or could not be made at all. We find then that amongst 22,250 children actually attending school, 114, or roughly 1 in 200 , were suffering from active, more or less acute, inflammation of the heart. The liability to this condition varies considerably with the age of the child. Bearing in mind what was said in the opening paragraphs, we are only entitled to use the ages $4,5,7,9,10$ and 12 , even for the roughest statistical purposes. The occurrence of endocarditis was at the following proportionate rates :-

9 at 4 years.
19 at 5 ",
15 at 7 ,
9 at 9 ",
16 at 10 ,
29 at 12,

We find also that of those cases in which a diagnosis of acute carditis could be made, or in which it was suspected (excluding 26 cases in which the result is uncertain, leaving 88 in which the result is known) 68 , or more than threequarters, developed into permanent heart disease. The history and associated conditions of these cases is worth consideration as throwing some light on their ætiology, and also demonstrating how really grave disease can be present in children presumed to be normal and living a normal child life. 
Excluding cases in which there is the least doubt, or exhibiting signs or symptoms the significance of which could not be determined with accuracy, we found that at the time of the first examiration :-

10 were suffering from active rheumatism and eight had a history of recent rheumatism.

13 were suffering from active chorea and six were recovering from recent chorea.

7 were recovering from recent scarlet fever.

7 were suffering from active nephritis.*

3 were suffering from chlorosis. $\dagger$

\section{Non-Organic Grour.}

In the course of inspection and in general medical work, numbers of cases; are met with in which murmurs are present, in which there is no serious damage to the heart. These murmurs are, however, of importance, because of their frequency, and bccause those who possess them are liable to be treated as though they had heart disease and to have their activity seriously curtailed. In the register these cases were divided into two classes, " hæmic " and " functional." At the present time this distinction seems rather trivial, but the history of the distinction is of some interest. In the nineteenth century it was well known that a large number of patients had heart murmurs which were not significant of organic disease Such murmurs were met with in cases of chlorosis and very frequently in children suffering from various chronic or acute diseases. They were generally considered to be due to some alteration in the state of the blood and were consequently called " hæmic murmurs." Though it was recognized that these murmurs were not significant of permenent damage to the heart, they were considered as of some consequence and calling for treatment.

When the medical in:pection of school children commenced, it was found that children not obviously ill frequently showed cardiac murmurs. As, at that period, these murmurs were looked upon as a sign of disease, they were recorded and ircluded amongst cases of organic disease. But it became obvious that the majority of these murmurs could not be significant of disease at all, for they occurred frequently in children who were absolutely healthy, whose hearts showed no other sign or symptom of departure from health, and the murmurs the msclves were temporary and variable. In the register, non-organic mumurs were therefore divided into two classes: those present in children who were absolutely healthy were called "functional"; and those present in children who were weakly, sickly, suffering from ill-nutrition, anæmia or various morbid conditions, were called "hæmic."

*There is strong reason to suspect that acute nephritis in childhood is a rheumatic infection. The facts that by far the commonest of all causes of nephritis in childhood is scarlet fever ; that the nephritis of scarlet fever is closely.connected with post-scarlatinal rheumatism ; that there is no significant difference between post-scarlatinal rheumatism and rheumatism which is not post-scarlatinal, and the present fict that some 7 per cent. of cases showirg acute endocarditis eventually ending in chronic heart disease are, at the time, suffering from acute nephritis, go some way to prove this contention.

†At the time these observations were made, chlorosis was not uncommon in girls of 12 in the district worked. 
TABLE 2.

Analysis of Cases Showing Functional Murmurs.

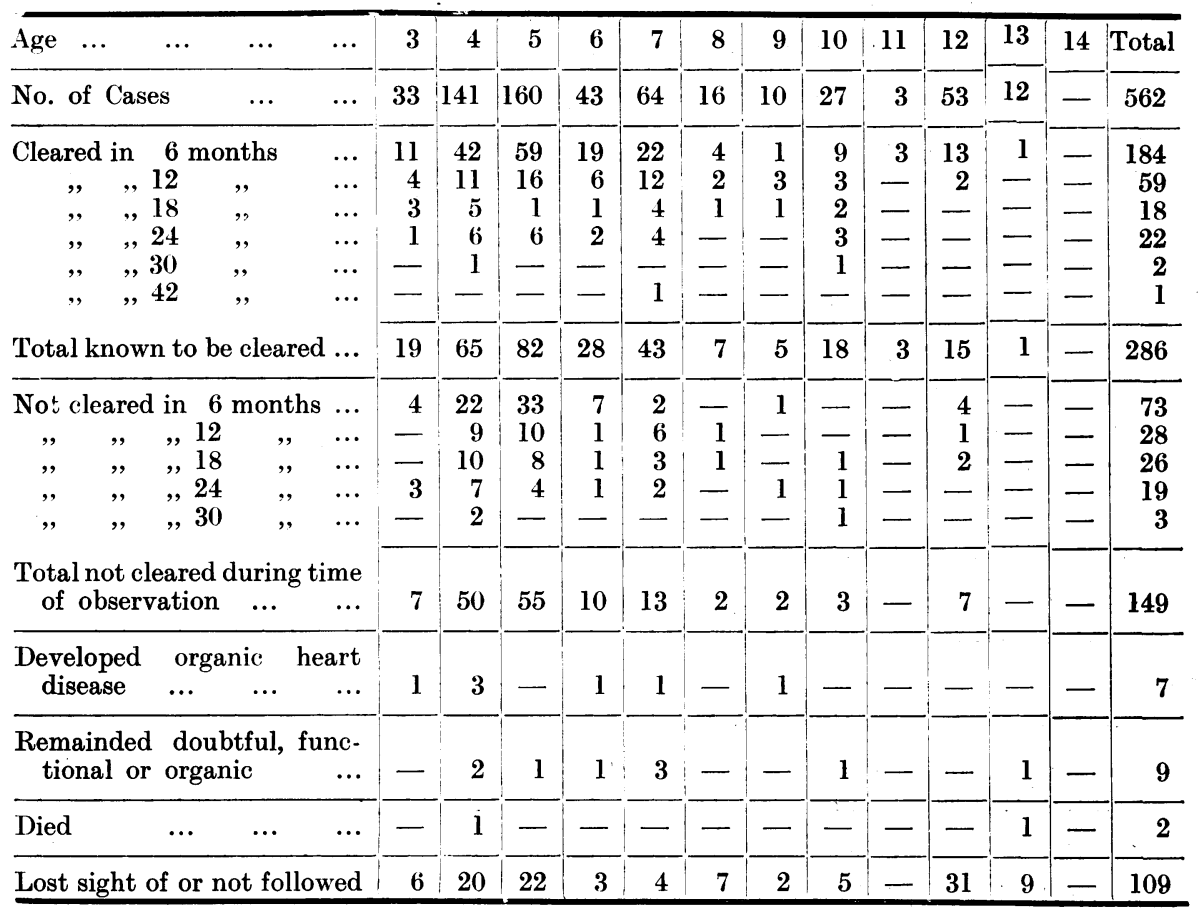

Group with Functional Murmurs.

A glance at Table 2 will show the most important facts in connection with the functional murmurs. They are frequent in young children, dwindle during the middle school period, and again become somewhat more frequent at twelve years of age, particularly in girls in whom puberty is commencing. Their age distribution is therefore entirely different from that of endocarditis, suggesting that they are temporary in character and tend to disappear about the time of the second dentition. The follow-up of these cases proves that they are, in the majority of cases, temporary peculiarities of children during the first dentition period.

562 such cases were registered, and the majority of them were followed up to the point when the heart sounds became, and remained, normal. The length of time that these murmurs existed could not be told for certain, but it could be told how long they lasted after they had been detected.

Of these cases (453 in number) which were followed up for a sufficient length of time for conclusions to be valuable, we get the following :-

Children aged 3.-27 cases followed. 11 had become normal in 6 months : 4 in 12 months ; 3 in 18 months ; 1 in 24 months ; 4 were still present after 6 months; 3 were still present after 24 months and 1 developed permanent. organic disease. 
Children aged 4.-121 cases followed. 42 cleared in 6 months; 11 in 12 months ; 5 in 18 months ; 6 in 24 months ; 1 in 30 months ; 22 had not cleared in 6 months; 9 had not cleared in 12 months; 10 had not cleared in 18 months ; $\mathbf{7}$ had not cleared in $\mathbf{2 4}$ months ; 2 had not cleared in 30 months. 1 died. In 2 the diagnosis remained doubtful to the end, and in 3 the diagnosis was altered to organic disease, or they developed organic disease while they were being watched.

Children aged 5.-138 cases followed. 59 cleared in 6 months ; 16 in 12 months ; 1 in 18 months; 6 in 24 months; 33 had not cleared in 6 months ; 10 had not cleared in 12 months ; 8 had not cleared in 18 months; 4 had not cleared in 24 months. In 1 the diagnosis remained doubtful.

Children over 5.-After the age of five years, the tendency is for these murmurs to clear more rapidly.

Of the total 453 at all ages, 184 were clear in 6 months, 243 in 12 months, 261 in 18 months, 283 in 24 months, 285 in 30 months and 286 in 42 months ; leaving 167 which had not cleared at the time the observations ceased. But of these 167, 73 had only been watched for 6 months and 28 had only been watched for 12 months. Amongst the 453 cases, 2 died of intercurrent diseases, 7 were eventually diagnosed as organic disease, and in 9 others the question remained doubtful at the end whether the condition was organic or not. If we take only the more certain cases that were re-diagnosed as organic, namely, 7 out of 453 , we see this is roughly 1.5 per cent., whereas the average chance of a child developing organic disease is under one per cent.; so it is possible either that these children with functional murmurs are slightly more liable to carditis than children with normal heart sounds, or that there is a slight error in considering as functional, murmurs which are really organic. It is worth noting that this error is small.

TABLE 3.

Analysis of 136 Cases Showing Hemic Murmurs.

\begin{tabular}{|c|c|c|c|c|c|c|c|}
\hline & & Number & $\begin{array}{c}\text { Not } \\
\text { followed }\end{array}$ & Cleared & \begin{tabular}{|c|} 
Not \\
cleared up \\
while \\
under \\
observation
\end{tabular} & $\begin{array}{l}\text { Became } \\
\text { organic }\end{array}$ & Died \\
\hline $\begin{array}{l}\text { Ill-nutrition, etc. } \\
\text { Tuberculosis } \ldots \\
\text { Diphtheria } \\
\text { Chlorosis } \\
\text { Chorea ... } \\
\text { Other conditions }\end{array}$ & $\begin{array}{l}\cdots \\
\cdots \\
\cdots \\
\cdots \\
\cdots \\
\cdots\end{array}$ & $\begin{array}{r}71 \\
17 \\
3 \\
2 \\
2 \\
38\end{array}$ & $\begin{array}{r}26 \\
2 \\
- \\
- \\
17\end{array}$ & $\begin{array}{r}26 \\
8 \\
3 \\
1 \\
1 \\
10\end{array}$ & $\begin{array}{r}17 \\
\frac{7}{1} \\
\frac{1}{10}\end{array}$ & $\frac{2}{-}$ & $\begin{array}{l}- \\
- \\
-\end{array}$ \\
\hline Totals & $\ldots$ & 133 & 45 & 49 & 35 & 4 & - \\
\hline
\end{tabular}

Since we had the division cf these non-organic murmurs into "functional" and " hæmic," it naturally follows that the present condition of the functional class was that of health, but when we consider their past history, we find that of the total 558, 4 had a history of rheumatism, 4 a history of pneumonia, 4 a history of scarlet fever and 2 a history of chorea ; and we find, what is most remarkable, that all four who had a history of rheumatism, and one of those 
who had a history of chorea, became " organic" and that the other with a history of chorea, died. When the history of these functional cases is compared with that of the endocarditis cases, the difference between them is striking. As generally nothing was known of these murmurs before they were discovered, there is no evidence whether they arose spontaneously, or whether they werc present from birth, but in five cases it is known that murmurs were not present some time before they were detected, and in six other cases the murmurs disappeared for a time and then came back again.

Group with Homic Murmurs.

As it has been explained, a distinction was drawn between "functional " and "hæmic" murmurs, the former being those murmurs present in healthy children and the latter those present in cases showing signs of ill-health.

Of the 136 cases registered as hæmic, 71 were suffering from various degrees of ill-nutrition, semi-starvation or anæmia. Of these, 21 cleared in 6 months, 4 in 12 months, 1 in 24 months ; 8 were not cleared in 6 months, 2 not cleared in 12 months, 5 not cleared in 18 months, and 2 not cleared in 24 months. One developed scarlet fever and subsequently organic heart disease and in 1 case the diagnosis was altered to organic disease. The result in 26 cases is unknown.

17 were suffering from tuberculosis and the remainder from various conditions. It is to be noted though, that only two either suffered from, or had a history of, chorea and only one of nephritis.

From the consideration of these two groups, the functional and the hæmic, it would certainly appear that the distinction is trivial and that there is no need to classify cardiac murmurs which are not organic.

\section{Group of Cardiac Curiosities.}

There were 42 curiosities ; 2 were transpositions, 2 displacements and 3 exocardial scratches. The remainder were curiosities of rhythm. These fall into two groups. The most abundant occur in young children. The normal rhythm of the young children is irregular, and the 22 cases recorded had extraordinary exaggerations of arrhythmia. They all became regular as they grew older. At the other end of the school age one meets with arrhythmia in boys over twelve, generally as the result of smoking, and arrhythmia in girls, generally at the beginning of menstruation.

\section{Discussion.}

From other registers compiled during school inspection, it was found that the proportion of cases showing abnormal heart condition was 36 per 1,000 (based on the examination of 25,000 children). This proportion is slightly less than in the heart register, which gives 42.5 per 1,000 , but the districts covered were not the same, and some of the cases (the curiosities) included in the heart register would not have appeared in the other.

Of 500 cases of adenoids for which operative treatment was advisable, 477 had normal hearts, 17 had functional murmurs and 6 had organic heart disease. From which we can conclude that there is no significant relationship 
between adenoids and heart conditions. Perhaps we may be allowed to extend this statement into saying that the antecedent causes of the adenoid condition and those of cardiac disorders are not similar.

Among 579 cases of rickets in school children, 32 had heart murmurs, none of which was organic. This gives a rate of about 56 per 1,000. Considering that the rickets children are a younger class than ' all' school children, there would appear to be no significant relationship between rickets and heart conditions.

\section{Conclusions.}

Presuming that the colliery district of Yorkshire is a fair sample of England and that the conditions present before the War are similar to those ruling to-day, we are justified in forming the following conclusions :-

1. The abnormal conditions of the heart discovered in elementary school children actually on the school register are of three kinds : permanent organic heart disease, active carditis and functional murmurs. That the first class may be considered as cripples ; the last class may be neglected as of no consequence ; and that the middle class, or carditis cases, call for active and special treatment which offers some promise of cure.

2. That the proportion of children that can be expected to exhibit functional murmurs is about 28 per 1,000 , permanent organic disease about 3.0 per 1,000 and active carditis about 5.0 per 1,000. Taking it that two-thirds of the last will end in permanent heart disease, it may be concluded that $6 \cdot 4$ per 1,000 , or one child in 160 , reaches the age of fourteen years with a permanently crippled heart.

3. That it would appear that, excluding congenital heart disease, there is one cause, and one cause only, of permanent heart disease in children, namely. rheumatism, assuming, as seems probable, that chorea, post-scarlatinal rheumatism and acute nephritis in childhood are rheumatic affections.

4. That the most important work of the school medical inspector in connection with the hearts of school children, is to recognize active carditis. School inspection should be an inspection and not a detailed examination, so that diagnosis is not one of its functions. The school inspector's work ends when he has found evidence to raise his suspicion. In connection with these heart conditions of children, the school inspector, while inspecting, must not be expccted to make a definite diagnosis of carditis, but he should be expected to refer for complete and detailed examination, every case in which the suspicion of carditis has been aroused during his inspection. 